\title{
Sustainable Information and Learning Access at a Rural University in Zimbabwe through a Mobile Application
}

\author{
Vusumuzi Maphosa, Bekithemba Dube, and Thuthukile Jita
}

\begin{abstract}
The current technological revolution must be harnessed to increase access to information and help communities in developing countries make informed decisions that can improve their standard of life. The purpose of this study was to develop an app that attempts to complement traditional media by improving access to timely and relevant information to enhance teaching and learning in deprived rural contexts. The process was guided by design science research methodology. The paper responds to three questions: the processes considered for effective development of apps in resource-constrained environments; the value of mobile apps in supporting teaching; and how mobile apps transform deprived rural institutions. As part of the design research, the rural-university community was engaged in the construction of an app enabling access to educational information, registration portals, fee balances, and coursework. The findings indicate that the app was useful, easy to learn, and provided utility to its users, which consequently transformed their university life. The paper concludes by arguing that in a deprived learning context, mobile apps have the impetus to bridge the rural-urban dichotomy and recentre rural contexts in a direction for sustainable learning.
\end{abstract}

Index Terms-Information and communication technology, mobile application, rural context, sustainable learning.

\section{INTRODUCTION}

Globally, the number of people that are online has increased and the developing world has witnessed the highest increase, with its impact on business, education, and social networks being enormous [1]. The mobile phone has become the most dominant and transformative technology for the developing world, offering endless possibilities to the way people communicate, access, and give information [2]. The mobile phone has evolved offering more computing power, larger memory, and bigger screens that easily facilitate integration with educational technologies which support teaching and learning [3]. Student engagement has been an important priority as most universities in developed countries have developed mobile phone apps that provide access to academic resources, campus maps, meal menus, and other services such as shuttle routes [4]. Park [5] noted that mobile technologies promote learner-centered activities where learning takes place at any time and any place, also offering opportunities for interaction and knowledge co-creation. Google has recognized the importance of student

Manuscript received May 12, 2020; revised November 11, 2020.

Vusumuzi Maphosa is with Lupane State University, Zimbabwean, South Africa

Bekithemba Dube and Thuthukile Jita are with University of the Free State, Zimbabwean, South Africa (e-mail: dubeb@ufs.ac.za). engagement by engaging developers to develop mobile apps for students coming from low-income regions, providing them with opportunities to access a virtual coach. The project launched by Google targets reaching over 250,000 students by 2020 [6]. One study revealed that students preferred using mobile devices for learning as these are more portable, affordable, and available [7]. This is even more relevant to rural learners, who may not have access to laptops and desktop computers. Yunfei [3] noted that apps create new learning opportunities by extending classrooms and learning hours.

Research revealed that $94 \%$ of teenagers go online every day to access educational and social-networking sites, check their phones 150 times a day and send at least 110 text messages per day [1]-[8]. In addition, other researchers established that college students check their mobile phones over 60 times a day and spend more than four hours a day glued to their mobile phones [9]. Research in Uganda showed that individuals with a post-secondary education are more likely to own a smartphone compared to those who are less educated [1]. Ninety-three per cent of those who had earned a post-secondary education owned a smartphone compared to $61 \%$ who owned a smartphone of those who were less educated.

Mobile phone ownership is highest among young people. Despite concerns that have been raised that they are always online, parents and guardians mainly provide young people with smartphones to enhance communication and allow them to access the internet [10]. This means that most students, even those in rural-based universities, are familiar with most mobile phone functions. Today's students have been described as the Millennial Digital Generation. This generation prefers to use mobile and other handheld devices for accessing educational materials, which covers flexibility and ubiquitous learning rather than being tied down to fixed desktop systems [3].

Telecommunications developments in the past few decades have seen mobile phone systems connecting to Wi-Fi, moving from $1 \mathrm{G}$, which supported voice, to $5 \mathrm{G}$, which supports multimedia applications that can support pedagogical practices [11]. Most universities have installed wireless technologies, thereby extending opportunities for interaction between lecturers and students. Mobile phones offer opportunities for learning to be facilitated beyond the confines of space and time, and has radically altered learning to be ubiquitous, instantaneous, and pervasive [12].

University and college students have been described as digital natives who are constantly connected to their digital devices [3]. Therefore, developing apps will present natural ways to access information and foster teaching and learning. In a similar study that was conducted in China by Mason and 
Zhang [13], it was found that $94 \%$ of learners utilized mobile apps to support their learning. Melhuish and Falloon [14] ascertained that the main benefits of using mobile apps were portability, affordability, ubiquitous access and just-in-time learning, connectedness, and personalized experiences. Bin et al. [11] concluded that time and space, which are associated with face-to-face learning, are being bridged by mobile devices. These devices are offering pervasive and ubiquitous information and activities to support learning.

A study which evaluated the use of mobile apps by 90 university students revealed that the majority of the student participants had accepted the university's app more as an aid in supporting their university experience than supporting their learning environment [15]. Yunfei [3] also noted that mobile apps are presenting new opportunities for staff and students, such as improved student engagement and integration of learning activities with other campus activities. Nikou and Economides [16] developed a mobile app that supports learners by enhancing their learning experience through utilising the ubiquity of mobile devices. The app developed by Nikou and Economides [16] is in line with the app developed for this study as it aims to allow students to engage with their campus-life activities as well as accessing academic information and bridging the digital chasm. As highlighted by scholars, who showed that the Millennial Digital Generation wants "anything, anyplace, and anytime" [11], [3], and in supporting the principles of ubiquitous and self-paced learning [14], we implemented the mobile app. Mobile apps offer features that can bridge the learner's environment and enable augmented realities [17]. One negative effect of using the developed app at a rural university could be low-speed Wi-Fi, as noted by Zou et al. [18], that some students use paper-based notes due to limited Wi-Fi access.

This study aimed to design an app that could enhance ubiquitous access to information in deprived learning contexts and bridge the technological divide through investigating students' perceptions on the utility of the app, based on design science research methodology (DSRM). The main questions this research sought to address are:

1) What are the processes that may be considered to effectively develop apps for rural resource-constrained environments?

2) Will students perceive using the app beneficial?

3) Does the app meet student expectations?

\section{LITERATURE REVIEW}

\section{A. Use of Mobile App in Multiple-deprived Learning} Contexts

Mobile phone applications provide exciting ways in which students can interact with technology by providing some intimacy and real information that the students expect. The potential that internet access has in the realm of education is enormous as it expands learning and teaching opportunities and presents prospects for enhancing student engagement [19]. There is a need to take advantage of the high prevalence of mobile phone usage among university students by providing educational services through apps. Rural areas are associated with limited infrastructure, yet mobile phones use little electricity, are easily deployed and accessible, and can be utilised in places where traditional learning may not easily take place [20]. Lupane State University (LSU) is a rural university located in the Matabeleland North province in Zimbabwe, with a student population of just over 4,000 students and about 400 academic and administrative staff. Limited funding for university education by the Zimbabwean government and poor economic performance provide great motivation for LSU to develop a mobile app for learning. Benefits of these apps were corroborated by Yunfei [3] to include flexible and creative learning, as well as personalized and collaborative learning.

\section{B. Situating the Gap: The Need for Mobile Apps for Learning in Zimbabwe}

Various studies have been carried out on the use of mobile apps in Zimbabwe, but none focused on the development of a mobile app to assist rural-university students and staff in multiple-deprived contexts. Mawere et al. [21] conducted a study on the use of mobile apps in Zimbabwe within the field of commerce to promote effective trade. They concluded the paper by arguing that there is a need for awareness tools and that citizens need to be trained and supplied with sufficient knowledge on how to use mobile-banking technology. Closer to the education sector, Maketo [22] conducted a study on mobile learning (m-learning) and argued that m-learning presents an opportunity to improve the quality of education in Zimbabwe. This is achievable provided the availability of cheaper mobile devices, and if Zimbabwe can bypass the fixed-telephony network and increase mobile phone networks. The study, although novel, focused on all universities, underscoring that different universities have different needs and, as such, most rural and deprived universities may benefit less compared to their urban counterparts. In another, related study, Sibanda and Musungwini [23] conducted research on m-learning in Zimbabwean polytechnic colleges to establish whether mobile computing is being used. The study concluded that Zimbabwean polytechnics have adopted usage of mobile computing to enhance their teaching and learning and administrative activities.

Informed by various studies in the field of technology, we argue that this paper is unique and contributes to the ongoing debate and growth of the field in many ways. First, we used DSRM to design an app for use by university students and staff members. The app was not imported from the West and implemented in an African and rural-Zimbabwe-university context. Rather, the design process included working with the local students and staff to develop an app that fits the needs of the deprived rural students. Second, the paper is unique in the sense that through the developed app, there is an attempt to bridge the urban-rural dichotomy. The aim is to assist rural learners and staff to be connected to the global world and, in the process, enhance teaching and learning in the deprived rural contexts. Lastly, the paper is unique in the sense that it argues that the mobile phone without a mobile app is not adequate. Thus, there is a need for the development of tailor-made apps that address the lived realities of students and staff in a particular context. In the following section, we 
discuss the methodology of this paper.

\section{RESEARCH METHODOLOGY}

This study chose DSRM, which has greatly impacted information research and practice by identifying problems, developing theory, and designing artefacts that solve real-world problems [24]. DSRM focuses on developing artefacts that must solve an existing societal problem through evaluating the provided utility [25]. DSRM provided the theoretical framework for the paper, which guided the development of the app as well as construction of the instrument used for evaluation. In this study, DSRM was used to develop an app that enhances access to information in rural-university Zimbabwe. The design process involved three stages, awareness, design, and evaluation as shown in Fig. 1. This is line with observations by Goggin and Clark [26], who criticized the imposition of technological solutions from the Global North on communities in developing countries, thereby possibly violating their cultural beliefs. A sample of 10 students from LSU was identified and was actively involved during the iterative-development process.

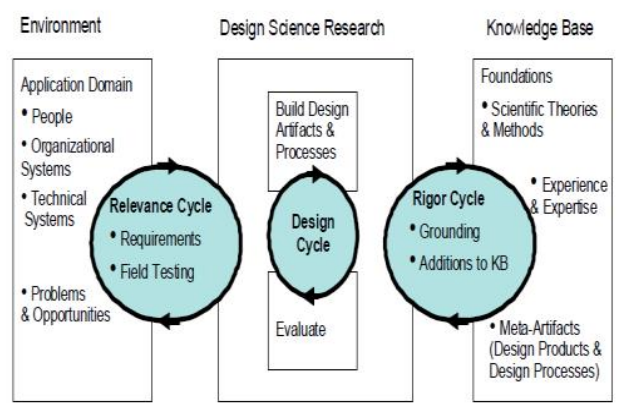

Fig. 1. Three-cycled design science research methodology [27]

\section{A. Awareness of the Problem}

Developing apps to augment traditional teaching and learning is more appropriate currently as most students now own smartphones and/or tablets. With well-developed pedagogical tools, students can carry their smartphones into their physical learning environment and enrich their learning experience [28]. Zou et al. [18] contended that the mobile phone and its features will continue to evolve until they fit well in the classroom. This agrees well with this research, which has the objective to develop a mobile app that improves access to information and resources that can support learning at a rural university. The awareness stage involves investigating and defining the problem as well as highlighting what would happen if it went unsolved [29]. After specifying the problem, the researcher must search the solution domain through reviewing literature and indicate alternative solutions and show how these could solve the problem. At the core of DSRM is the involvement of the user in problem specification, and building, testing and evaluating the artefact [25]. The use of DSRM allowed LSU stakeholders to be involved in the creation of the app so that it addresses their lived realties.

\section{B. Design Cycle}

The second stage of the DSRM process involved comprehension of the problem faced by university students and lecturers in accessing information, and suggestion of collective solutions that can address the problem. After agreeing on the information-access challenge, we proposed to develop an app that helps in narrowing the digital divide by allowing university students and staff to access information timeously. At each stage of developing the app, user feedback was used to improve the design and refine the user requirements. Scholars have depicted the DSRM process as a generating cycle, where each iteration is tested based on the specified requirements and user feedback is used to refine the design [27]. Venable [30] noted that developing a solution could range from simply a small refinement of an existing solution to a totally new invention.

To implement the app, a number of programming packages were used, which included Java and PHP, and the database was developed using MySQL. With LSU being situated in a rural context means that the number of internet service providers are few and internet provision is sometimes slow and unreliable. In an effort to increase usability, the mobile app was designed to support low bandwidth by using the Adobe AIR network interface API, which checks the availability of mobile internet on the user's phone [31]. Once the API service detects that the user has no or limited internet connection, it activates offline access. During the offline-access mode, the user accesses the core functions of the app from the local storage. Once a stable internet connection has been restored, device storage and cloud storage are synchronized so that any changes that were made to the local database are synchronized with the server.

The design stage involved developing paper-based sketch prototypes, which were presented to the participants for evaluation during the within the design phase. A use case was developed for participants, to highlight how they would interact with the app, as shown in Fig. 2a. During iterative-design sessions, participants suggested changes to the screen graphics, arrangement of icons and content, as shown in Fig. 2b.
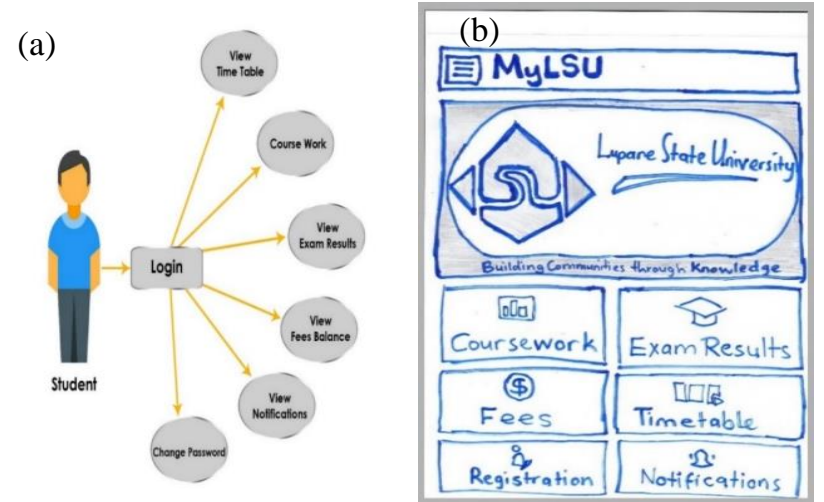

Fig. 2. (a) Student use-case model; (b) main screen layout.

During the design stage, the group of participants settled on the content that must be conveyed by the app. This included aspects such as university activities, including meal menus and bus timetable; modules; cancellation of lectures; and platform for accessing examination results (Fig. 2b). These sessions provided rich user feedback, which determined the changes that had to be made during the iterative-design changes. Participants suggested that standard 
icons should be developed which must guide the user on the menu or action to perform.

Once the participants had agreed on the main functions of the app and the general layout of the icons, the next iterative step was the development of high-fidelity prototypes. Design considerations included the layout of hierarchical menus, display layout, icon menus, navigation, and other elements that foster usability. Once a complete version was developed, the participants were required to make an evaluation and this continued until a working prototype had been developed. This approach ensured that user needs were constantly incorporated into every stage of the development. When the developers and potential users agree on the final version of the prototype, it is uploaded onto the mobile platform for potential users to evaluate its usability and functionality. This is to ascertain that the prototype meets the users' requirements. The app runs on the Android operating system, which controls $86.2 \%$ of the global market and is the most predominant operating system in the Global South [32]. Some screenshots of the final app prototype are shown in Fig. 3.

TABLE I: STANDARD DEVIATION AND MEAN FOR MYLSU APP

\begin{tabular}{|c|c|c|c|c|c|c|c|c|}
\hline & $\begin{array}{l}\text { Relevant } \\
\text { content }\end{array}$ & Visual appeal & Functionality & Reliability & Satisfaction & Easy to learn & $\begin{array}{l}\text { Recover from } \\
\text { errors }\end{array}$ & $\begin{array}{l}\text { Would } \\
\text { recommend }\end{array}$ \\
\hline $\mathrm{N}$ valid & 80 & 80 & 80 & 80 & 80 & 80 & 80 & 80 \\
\hline Mean & 4.525 & 4.213 & 4.100 & 4.400 & 4.275 & 4.316 & 4.475 & 3.988 \\
\hline Std. Deviation & 0.656 & 0.544 & 0.587 & 0.704 & 0.675 & 4.313 & 0.718 & 0.626 \\
\hline Variance & 0.430 & 0.296 & 0.344 & 0.496 & 0.455 & 0.648 & 0.516 & 0.392 \\
\hline Minimum & 3.00 & 3.00 & 3.00 & 3.00 & 3.00 & 3.00 & 3.00 & 3.00 \\
\hline Maximum & 5.00 & 5.00 & 5.00 & 5.00 & 5.00 & 5.00 & 5.00 & 5.00 \\
\hline
\end{tabular}

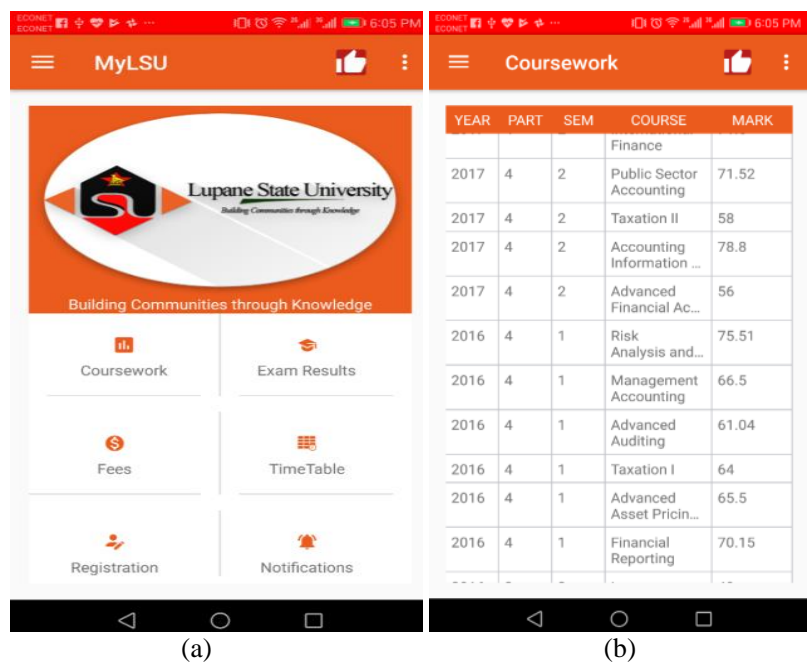

Fig. 3. Screenshots of the final high-fidelity app prototype showing (a) menu and (b) coursework.

\section{Evaluation}

Most apps developed by universities are available for free and always accessible, offering students access to information and resources. After the prototype for this study was successfully uploaded into a mobile platform, the next stage was the evaluation of the mobile app to establish the effectiveness of the app to address the lived realities of the participants. The objectives spelt out in the relevance cycle of the DSRM together with the identified problem were evaluated to determine if the proposed artefact provided the perceived functionality and utility. Hevner et al. [27] concluded that the artefact's utility must be demonstrated by measuring its effectiveness and usefulness through applying an evaluation matrix. The purpose of the evaluation was to determine how the proposed app could address information-access challenges at the rural university. The participating students who were part of the development team were excluded from the evaluations so as to obtain unbiased responses. A questionnaire adapted from Harrison et al. [33] was used to assess usefulness, user satisfaction and learnability of the mobile app among university students.
Respondents were asked to evaluate the app after having used it for 14 days.

\section{RESUlts}

Using random sampling, 100 students were targeted to evaluate the usefulness and effectiveness of the mobile app through a questionnaire. Students and staff who were involved in the development of the app were excluded from evaluation so as to obtain unbiased responses of the mobile app. Eighty questionnaires were successfully completed, giving a response rate of $80 \%$. To evaluate the utility of the app in supporting learning at the rural university, we designed the survey instrument using a Likert scale, with 1 being 'Strongly Disagree' and 5 being 'Strongly Agree'. Table I provides a summary of the results of the study.

The results of the study reveal that $100 \%$ of the student respondents owned a mobile device, whereas $35 \%$ owned more than one mobile device. In responding to how they accessed the app, $90 \%$ of respondents indicated that they accessed it from their smartphones, whereas the remaining $10 \%$ accessed it through their tablet devices. About $90 \%$ of the respondents enjoyed using the app, as demonstrated by their scoring of 4 or 5 on the questions related to usefulness and ease of use. This is in line with work by Viswanathan [34], who posited that learning apps increased students' enthusiasm and motivation. This proves that using mobile devices as a learning- and information-access tool is beneficial to students at LSU. The values observed for standard deviation was low, ranging from 0.544 to 0.718 , which means that the responses are close to the central tendency. The next step was the evaluation of the mobile app to establish the effectiveness of the app to address the lived realities of the participants. About $40 \%$ of the respondents owned a laptop, whereas only $10 \%$ owned a desktop computer and $0 \%$ a landline telephone.

Regarding the overall visual-appeal and layout aspects, the respondents liked the interface of the application $(M=4.2$, $S D=0.5)$. The results show that the respondents strongly 
agreed that the design of the app was appealing and intuitive, that it was pleasant to use and that information was clearly presented. The majority of the respondents agreed that the app provided the desired functionality and capabilities $(M=4.1, S D=0.59)$, meaning that they could effectively retrieve and access information. The app was also evaluated for reliability, to which respondents agreed that all the features in the app functioned well $(M=4.4, S D=0.7)$. One major determinant of the utility of an app is its learnability, to which respondents agreed that it was easy to learn to use the app $(M=4.3, S D=0.648)$. The respondents felt that it was easy to find the required information and services and this means that they would not require any assistance to use the app. In general, the respondents felt comfortable and satisfied using the app $(M=4.28, S D=0.67)$.

Respondents agreed that they could recommend the app to their colleagues and would gladly use the app in the future $(M=3.99, S D=0.63)$. This is similar to findings by Briz-Ponce et al. [8] observed that $57 \%$ of participating students were willing to use the relevant mobile app and recommend it to others. For this study, respondents agreed that the app allowed them to quickly recover from errors or easily rectify a mistake they would have made during the operation $(M=4.475, S D=0.72)$. Overall, the app was rated well in terms of meeting the expectations of users, as evidenced by $88 \%$ of the respondents choosing 'Strongly Agree' and 'Agree' on the questions asked. During the app-development process, we had to be cognisant of poor internet connectivity in a rural setup and thus developed an app that can support offline access. To enhance usability, the iterative-development processes involved potential users so that their requirements were captured. The limitation of this study is that there were no pre- and post-implementation assessments to empirically determine the actual improvements brought on by the app.

\section{CONCLUSION}

The effect of mobile apps on Millennials has been enormous, with opportunities provided to develop apps that support their learning. The paper argued that in a deprived learning context, mobile apps have the impetus to bridge the rural-urban dichotomy and recentre rural contexts in a direction for sustainable learning. The objective of this research was achieved through the development and evaluation of a mobile app for learning. The app enhanced access to information at a rural university with technological limitations which hinder accessing information. Our study provided a comprehensive overview of the development process and demonstrated the iterative steps that were taken. The paper also examined how students utilized the developed app. The evaluation results demonstrated the utility and effectiveness of the app in enhancing information access and student engagement. In responding to questions after having used the app, an average of $90 \%$ of respondents chose 'Strongly Agree' and 'Agree' regarding the relevance of the content, visual appeal, functionality, reliability, ease of learning, and satisfaction. Overall, these results show significant interest and positive attitude towards the use of the app by students, implying that they considered the app to be useful and easy to use.

\section{CONFLICT OF INTEREST}

The authors declare no conflicts of interest.

\section{AUTHOR CONTRIBUTIONS}

Dr. Vusumuzi Maphosa wrote the Introduction and Literature Review in the study. He was responsible for conducting the data collection, and collaborated with the other authors in writing the methodology, results and conclusion.

Dr. Bekithemba Dube formulated the problem statement and the research questions of the study. The literature review of existing studies was done under his guidance.

Dr. Thuthukile Jita designed the methodology of the research and closely supervised the questionnaire formation. In addition, she worked extensively on data analysis and interpretation of the results. The paper was continuously edited under her guidance.

All the authors have approved the final version of the paper.

\section{ACKNOWLEDGMENT}

This work was supported by the South African National Roads Agency Limited (SANRAL) and the National Research Foundation (NRF reference number: TTK170405225946).

\section{REFERENCES}

[1] Pew Research Center. (2017). Mobile Fact Sheet. [Online]. Available: http://www.pewresearchcenter.org/mobile-fact-sheet

[2] J. Wang, W. Yu, and E. Wu, "Empowering mobile assisted social e-learning: Students' expectations and perceptions," World Journal of Education, vol. 3, no. 2, pp. 59-70, 2013.

[3] D. Yunfei, "Information use and barriers on a mobile app in distance learning," Journal of Library \& Information Services in Distance Learning, vol. 9, no. 3, pp. 204-220, 2015.

[4] O. Yilmazel and E. Ekin, "Mobile applications at a mega university: Anadolu University," AAOU, vol. 10, no. 1, pp. 13-21, 2015.

[5] Y. Park, "A pedagogical framework for mobile learning: Categorizing educational applications of mobile technologies into four types," Review of Research in Open and Distributed Learning, vol. 12, no. 2 , pp. 78-102, 2011.

[6] Google+. (2015). [Online]. Available: https://plus.google.com/+google/posts/fRHuW7PoV5Y

[7] E. Sung and R. Mayer, "Students' beliefs about mobile devices vs. desktop computers in South Korea and the United States," Computers \& Education, vol. 59, no. 4, pp. 1328-1338, 2012.

[8] L. Briz-Ponce, A. Pereira, L. Carvalho, J. Juanes-Méndez, and F. J. García-Peñalvo, "Learning with mobile technologies: Students' behavior," Comput. Hum. Behav, vol. 72, pp. 612-620, 2017.

[9] A. Lepp, J. Barkley, and A. Karpinski, "The relationship between cell phone use, academic performance, anxiety, and satisfaction with life in college students," Computers in Human Behavior, vol. 31, pp. 343-350, 2014.

[10] A. Lenhart. (2012). Teens, smartphones \& texting. [Online]. Available: http://pewlnterne-t.org/ Reports/2012/Teens-and-smatphones.aspx

[11] Z. Bin, L. Hui, and L. Jiaying, "Exploring a curriculum app and a social communication app for EFL learning," Computer Assisted Language Learning, vol. 31, no. 7, pp. 694-713, 2018

[12] O. Boyinbode, A. Bagula, and D. Ngambi, "An opencast mobile learning framework for enhancing learning in higher education," International Journal of $u$ - and e-Service, Science and Technology, vol. 4, no. 3, pp. 11-18, 2011

[13] A. Mason and W. Zhang, "An exploration of the use of mobile applications to support the learning of Chinese characters employed by students of Chinese as a foreign language," in Beyond the Language 
Classroom: Researching MOOCs and Other Innovations, K. Qian, and S. Bax, Dublin, Ireland: Research Publishing, 2017, pp. 99-112.

[14] K. Melhuish and G. Falloon, "Looking to the future: M-learning with the iPad computers in New Zealand schools," Learning, Leading, Technology, vol. 22, pp. 1-16, 2010.

[15] S. Kinash, J. Brand, and T. Mathew, "Challenging mobile learning discourse through research: Student perceptions of Blackboard Mobile Learn and iPads," Australasian Journal of Educational Technology, vol. 28, no. 4, pp. 639-655, 2012.

[16] S. Nikou and A. Economides, "Mobile-based assessment: Investigating the factors that influence behavioral intention to use," Comput. Educ, vol. 109, pp. 56-73, 2017

[17] J. M. Zydney and Z. Warner, "Mobile apps for science learning: Review of research," Computers \& Education, vol. 94, pp. 1-17, 2016

[18] B. Zou, H. Li, and J. Li, "Exploring a curriculum app and a social communication app for EFL learning," Computer Assisted Language Learning, vol. 31, no. 7, pp. 694-713, 2018.

[19] J. Hughes, A. Burke, and L. Morrison, "The adolescent bricoleur: Constructing, deconstructing and reconstructing social and personal identities through social networking sites," World Social Science Forum, vol. 5, no 2, pp. 87-107, 2013.

[20] J. Kim, N. Chung, and C. Lee, "The effect of perceived trust on electronic commerce: Shopping online for tourism products and services in South Korea," Tourism Management, vol. 32, no. 2, pp. 256-265, 2011.

[21] T. Mawere, P. Denhere, M. Giyane, T. Mzikanwi, and P. Mupfiga, "An analysis of mobile banking adoption in Zimbabwe," Journal of International Academic Research For Multidisciplinary, vol. 1, no. 8, pp. 423-433, 2013.

[22] L. Maketo, "Mobile learning model for Zimbabwe higher education," The Tenth International Conference on Mobile, Hybrid, and on-Line Learning, Rome, pp. 4-10, 2018.

[23] M. Sibanda and S. Musungwini, "Investigating the use of mobile computing in Zimbabwe polytechnics: Case of a polytechnic in Zimbabwe," International Journal of Scientific \& Technological Research, vol. 4, no. 7, pp. 121-125, 2015.

[24] M. Helfert, B. Donnellan, and I. Ostrowski, "The case for design science utility and quality - Evaluation of design science artifact within the sustainable ICT capability maturity framework," Information Technology, Action, Communication and Workpractices vol. 6, no. 1, pp. 46-66, 2012.

[25] A. Hevner and S. Chattejee, Design Research in Information Systems. Theory and Practice, New York: Springer, 2010.

[26] G. Goggin and J. Clark, "Mobile phones and community development: A contact zone between media and citizenship," Development in Practice, vol. 19, pp. 585-597, 2009.

[27] A. R. Hevner, S. T. March, and J. Park, "Design research in information systems research," MIS Quarterly, vol. 28, no. 1, pp. 75-105, 2004.

[28] Y. Song, "'Bring Your Own Device (BYOD)" for seamless science inquiry in a primary school," Computers \& Education, vol. 74, pp. 50-60, 2014.

[29] R. Wieringa, "Design science as nested problem solving," in Proc. the 4th International Conference on Design Science Research in Information Systems and Technology, Philadelphia, vol. 1, no. 1, pp $25-40,2009$

[30] J. Venable, "Identifying and addressing stakeholder interests in design science research: An analysis using critical systems heuristics," IFIP
Advances in Information and Communication Technology, vol. 301, pp. 93-112, 2009 .

[31] Android Developers. (2014). API Guides. [Online]. Available: https://developer.android.com/guide/topics/ui/layout/gridview.html

[32] Quartz. (2017). More Android apps are downloaded in India than anywhere else in the world. [Online]. Available: https://qz.com/886985/india-logged-the-most-android-app-downloads -and-usage-in-2016/

[33] R. Harrison, F. Flood, and D. Duce, "Usability of mobile applications: Literature review and rationale for a new usability model," Journal of Interaction Science, vol. 1, no. 1, pp. 1-42, 2013.

[34] R. Viswanathan, "Augmenting the use of mobile devices in language classrooms," International Journal of Computer-Assisted Language Learning and Teaching, vol. 2, no. 2, pp. 45-60, 2012.

Copyright $(92021$ by the authors. This is an open access article distributed under the Creative Commons Attribution License which permits unrestricted use, distribution, and reproduction in any medium, provided the original work is properly cited (CC BY 4.0).

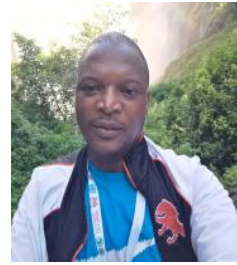

Vusumuzi Maphosa is the director at Lupane State University's Information and Communication Technology and Services Department, Zimbabwe. He pursued his $\mathrm{Ph} . \mathrm{D}$. in information systems and technology at the University of KwaZulu-Natal (UKZN), South Africa. He has over 10 years' experience in IT administration and teaching, with two years of experience in research focusing on information and communications technologies for development (ICT4D), data mining, educational technology and e-governance.

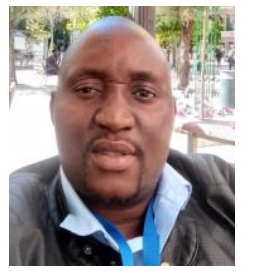

Bekithemba Dube holds a doctor of philosophy in curriculum studies from the University of the Free State. He is currently a senior lecturer and a discipline coordinator at the University of the Free State. He is the managing editor of the African Journal of Education in Rural Contexts. His area of research is in curriculum studies, religious education, and politics in postcolonial states.

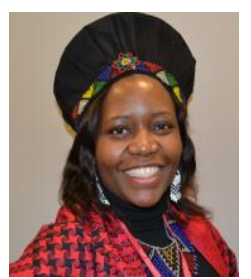

Thuthukile Jita is a senior lecturer, discipline coordinator for Curriculum Studies and the research coordinator for the Instructional Leadership and Curriculum Implementation Studies (ILCIS) group in the Faculty of Education at the University of the Free State (UFS). She is also an elected member of the UFS Senate and serves on the Faculty of Education ethics committee. She is an experienced instructional designer, and science educator, with many years of involvement in engaged-scholarship projects with national and international schools. Dr Jita is also a Thuthuka, National Research Foundation (NRF) grant-holder. She has six years of teaching experience at higher education institutions, five years as an instructional designer and thirteen years as a teacher. Her research interests include curriculum studies, pre-service-teacher education, use of Information and Communication Technologies (ICTs) and science education. 